\title{
ANÁLISE DOS PROCESSOS DE INTERPRETAÇÃO TEXTUAL EM LÍNGUA ESTRANGEIRA
}

\author{
Iris Oliveira de Carvalho*
}

\begin{abstract}
Resumo
O processamento do texto lido está além do simples reconhecimento das palavras. Para compreender um texto, é necessário o uso de mecanismos interpretativos baseados no conhecimento do código, do tema e na reconstrução dos valores sociais, ideológicos e culturais estabelecidos pelo autor durante a construção do texto. A leitura em língua estrangeira compreende os mesmos mecanismos interpretativos, entretanto exige o conhecimento sociocultural na língua-alvo. Assim, a partir da leitura em língua estrangeira, analisamos, neste artigo, os processos através dos quais os leitores negociam o sentido interpretando textos.
\end{abstract}

Palavras-chave: interação, interpretação, leitura.

Foreign lenguage textual interpretation analyses process

\section{Abstract}

The processing of the read text is beyond the simple recognition of the words. To understand a text, the use of interpretation mechanisms based in the knowledge of the code and subject are necessary. Necessary as well are the cultural, ideological and social reconstruction values established by the author during the text construction. The reading in foreign language uses the same interpretation mechanisms, however it demands the sociocultural knowledge of the target language. Thus, from the reading in foreign language we analyze in this article the processes through which the readers negotiate the meaning of the meaning of the text making its interpretation.

KEY wORDs: comprehension, interaction, reading.

\section{INTRODUÇão}

Ao compreender uma enunciação discursiva, o leitor é capaz de construir uma representação mental dentro de seu contexto sociocultural, como parte do processo de compreensão do discurso. A leitura, ao implicar uma interação social entre o locutor/emissor e o receptor/leitor, é uma atividade cooperativa. De acordo com Grice (1989), segundo

* Mestre em Lingüística Aplicada ao Ensino de Língua Estrangeira/ Espanhol, professora de Língua Espanhola no Cepae/ UFG. E-mail - irisoc@uol.com.br 


\section{Revista Solta a Voz, v. 16, n. 1}

os princípios de cooperação, autor e leitor fazem uso de estratégias de conversação como uma maneira de compensar as possíveis dificuldades provenientes da leitura, ou seja, buscam o estabelecimento da compreensão do texto na interação leitor-autor. Nesse processo, o autor dá as pistas enunciativas para o leitor obedecendo a princípios de cooperação (quantidade e qualidade da informação, relevância e organização do discurso). Assim, o que se percebe nessa comunicação é que há um esforço por colaborar com o interlocutor, pois os falantes têm algum propósito comum mais ou menos definido e se esforçam em alcançá-lo. Quando o autor e o leitor possuem universos contextuais diferentes, ou se houver um mal-entendido na compreensão dos enunciados no texto, podem ocorrer discrepâncias na interpretação do texto lido.

\section{O PROCESSO DE LEITURA}

Para Kato (1999), a velocidade e a precisão com que uma palavra é lida, percebida ou compreendida dependem de seu registro ou não no léxico visual do falante, ou seja, pela freqüência com que o leitor já foi exposto a ela é que ele a tem acoplada ao seu sentido visual. Entretanto, o reconhecimento instantâneo de palavras não explica a leitura fluente com compreensão, já que envolve um processo de decodificação de estruturas maiores como os sintagmas, por exemplo, além de um bom componente de adivinhação e inferência. Segundo Kleiman (2001), o processamento da leitura se dá inicialmente pelos olhos, que permitem a percepção do material escrito. A partir daí, o que foi apreendido visualmente passa, então, para a memória de trabalho, que organiza os dados em unidades significativas. Nesse processo está também a memória intermediária, que armazena e deixa à disposição do leitor as informações necessárias para a compreensão do texto. A memória intermediária está inserida na memória de longo prazo, também conhecida como memória semântica ou, ainda, memória profunda, a qual organiza todo o conhecimento e regras para o uso e organização das informações armazenadas na memória intermediária e que estão em alerta e poderão ser ativadas quando necessário.

Assim, de acordo com Rumelhart (1977), ler é um processo de interação ou de influência mútua entre o texto e o leitor. É por meio de seu conhecimento prévio que o leitor constrói um significado compreensível do texto ao relacionar o que o texto diz com o que já conhece. 
Segundo Kato (1999), na área da compreensão de leitura, em que ocorrem processos não-observáveis diretamente, duas concepções radicalmente opostas dominaram o cenário das investigações: a hipótese ascendente (botton-up), ou seja, dependente do texto, e a hipótese descendente (top-down), ou dependente do leitor. Assim, de acordo com Eskey (1988, p. 87),

[também] é interativa a relação entre informação obtida através da decodificação, ou seja, o processamento de informação bottom up e a proporcionada pela capacidade interpretativa do leitor, o processamento de informação top down.

Para Bielsa (2000), compreender um texto é comprovar os conhecimentos prévios do leitor ou reestruturá-los. E, por sua vez, a informação desse texto pode ser enriquecida com as contribuições próprias do leitor.

De acordo com Mayor (2000), a compreensão leitora apresenta quatro dimensões básicas: o texto, a atividade do leitor, o sistema lingüístico utilizado e o contexto. A dimensão do texto pode ser entendida através de sua organização, de suas funções comunicativas, sua intencionalidade, que aparecem explícita ou implicitamente em suas propriedades de legibilidade e adequação. A atividade do leitor é entendida especialmente em seu condicionamento para a leitura - a motivação e a aprendizagem, as expectativas comunicativas em relação ao input do texto e o output - ou seja, o resultado da compreensão leitora é que pode ou não se traduzir depois em uma atividade externa. $\mathrm{O}$ sistema lingüístico engloba os diferentes códigos estruturais, que podem ser gráficos ou ortográficos e são estruturados da seguinte forma: fonológicos e sintáticos e os substanciais (léxicos e semânticos). A dimensão do contexto abarca os diferentes contextos, dos situacionais até os interpessoais, e também os estritamente cognitivos, como o cultural, o histórico e o social, através dos quais operam representações mentais que o sujeito tem de sua realidade.

Segundo Cavalcanti (1989), a interação leitor-texto tem por base não apenas a competência comunicativa dos leitores como também seus sistemas de crenças ou valores, que influenciam e são influenciados por variáveis de desempenho. Assim, esses sistemas de crenças e valores englobam ideologia, religião, moral, estética etc. 


\section{Revista Solta a Voz, v. 16, n. 1}

Para Mey (2001), a leitura é uma atividade colaborativa entre autor e leitor. $\mathrm{O}$ trabalho do autor é suplementado e complementado pelo leitor. O leitor, como colaborador ativo, adentra no universo criado pelo autor, entra em contato com as restrições do texto, mas também encontra nele pontos de liberdade, os quais colaboram com o autor para construir o universo textual apropriado para sua compreensão.

\section{TIPOS DE LEITOR}

De acordo com Kato (1999), para a concepção ascendente, o leitor ideal é aquele que analisa cuidadosamente o input visual e que sintetiza o significado das partes menores para obter o significado total do texto. Esse é chamado de leitor analisador. Para a concepção descendente, o leitor idealizado se apóia, principalmente, em seus conhecimentos prévios e em sua capacidade inferencial para predizer o que o texto dirá, utilizando a memória intermediária apenas para diminuir as incertezas. Esse é chamado de leitor construtor.

Outro tipo de leitor é o cooperativo, pois em qualquer comunicação seja ela escrita ou falada existe a interação entre produtor e compreendedor, e, especialmente, na comunicação escrita não estão presentes pistas contextuais como os gestos, o universo semântico e regras conversacionais como os turnos, nos quais o interlocutor pode esclarecer pontos obscuros durante a interação conversacional. Dessa maneira, segundo Grice (1989), através dos princípios de cooperação, ou seja, esse acordo, tácito, de colaboração na tarefa de comunicar-se, a interação se dá entre leitor-escritor. A comunicação é regida por regras conversacionais e o escritor procura ser (segundo as leis da cooperação) informativo, sincero, relevante e claro. Nesse caso, o leitor tem a função de compreender as intenções e objetivos do autor. Se algum princípio for violado, o leitor deverá entender que o autor o fez intencionalmente e que está tentando dizer algo, que deve ser decifrado por ele. Ocorre que muitas vezes os significados inferidos no texto não têm necessariamente relação com as intenções do autor, que não pensou em possíveis interpretações do leitor, mas que são autorizadas pelo texto.

Existe, ainda, o leitor reconstrutor, derivado de uma concepção de texto que considera este como uma unidade formal, ou seja, uma unidade de comunicação. Assim, a leitura seria um ato de reconstrução dos processos de sua produção. De acordo com Levy (1979), a leitura é 
Revista Solta a Voz, v. 16, n. 173

um ato de reconstrução dos processos de produção, os quais, para Kato (1999), dariam conta da interação leitor-autor, já que esta não se centra no texto já estruturado, mas na simulação de sua construção. Dessa maneira, ao ler, o leitor acompanha o pensamento do autor, de modo que o texto seria um conjunto de pegadas a serem seguidas para recapitular as estratégias do autor e através delas chegar aos objetivos. No modelo de Levy, a produção escrita é vista como um processo de planejamento, em que o autor codifica os objetivos da mensagem por meio de estratégias comunicativas. Assim, o leitor reconstrutor utiliza as mesmas regras que regem o comportamento do autor, inclusive suas representações mentais. No caso da leitura em língua estrangeira, se o leitor não possuir uma competência comunicativa em língua estrangeira equivalente à do autor, o processo de reconstrução dos objetivos e de representação mental do texto está visivelmente comprometido.

\section{LEITURA COMO PRÁTICA COMUNICATIVA}

Para Canale (1995), não se pode mencionar a abordagem comunicativa sem relacioná-la com a natureza da comunicação, sem proceder à distinção entre competência comunicativa e comunicação real e os principais componentes da competência comunicativa. Assim, algumas características básicas da natureza comunicativa seriam: a comunicação como mecanismo de aquisição e de uso da língua, mediante interação social; uma linguagem autêntica oposta à linguagem inventada dos livros; a busca de situações de uso cotidiano da linguagem, ou seja, o contexto discursivo e sociocultural, que regem o seu uso apropriado e oferecem referencial para uma interpretação satisfatória das expressões que se apresentem; comunicação como intercâmbio e negociação de informação entre indivíduos, por meio do uso de um mesmo sistema lingüístico, em processos de produção e compreensão.

Sob essa perspectiva, a competência comunicativa é entendida como um conjunto de habilidades requeridas para a comunicação, tais como: o conhecimento de vocabulário e estruturas gramaticais e ordenação sintática das frases, por exemplo. Dessa forma, a competência comunicativa compreenderia o conhecimento da língua e a habilidade para colocá-la em uso, quando é parte de uma comunicação real. A competência comunicativa estaria, então, dividida em pelo menos quatro áreas de conhecimento e habilidades: competência gramatical; 


\section{Revista Solta a Voz, v. 16, n. 1}

sociolingüística (mais tarde redividida em sociocultural); discursiva e estratégica. Somando-se a tudo que já foi dito estão as quatro destrezas: compreensão auditiva, compreensão leitora, expressão escrita e expressão oral. Essas destrezas, de acordo Espinet (1997), em um enfoque comunicativo adquirem uma importância explícita e integrada. Como a aprendizagem comunicativa requer interação, raras vezes na comunicação real utilizamos uma destreza isoladamente, pois geralmente elas estão integradas e são de uso simultâneo.

Para Hernández (1990), a leitura comunicativa serve para consolidar os conteúdos aprendidos e para a ampliação paulatina de vocabulário. O objetivo da leitura no ensino comunicativo é habituar o aprendiz a ler vários tipos de textos autênticos, sem a necessidade de tradução. Logo, a leitura de obras literárias ou de livros de leituras complementares é uma prática para atender às necessidades de um desenvolvimento progressivo e eficaz da compreensão de leitura, a qual pode ser entendida como um mecanismo para a aquisição de vocabulário e de novas estruturas. Leituras mais complexas sugerem o uso de estratégias e recursos para a sua compreensão, como o uso do dicionário, a compreensão da idéia central do texto, uma explicação prévia ou a prática da dedução.

Segundo Widdowson (1991, p. 113), o que buscamos desenvolver em nossos aprendizes, utilizando uma prática comunicativa de leitura, é a capacidade de trabalhar com discurso autêntico, em que "o critério de realidade é uma característica da relação entre o texto e o leitor e isso tem a ver com a resposta apropriada nessa tarefa". O aprendiz, ao estar motivado para ler um texto específico, frustar-se-á se as dificuldades lingüísticas do texto forem tantas a ponto de ele não conseguir processá-las. Vale destacar que a capacidade comunicativa pressupõe habilidades lingüísticas, e grande parte da capacidade de ler está na capacidade de compreender, seja explícita ou implicitamente pelo contexto, os aspectos culturais da língua-alvo que possibilitem essa compreensão. Portanto, o que devemos fazer é dar um suporte de apoio para esse aprendiz enfrentar possíveis problemas com o texto, estruturas sintáticas ou itens lexicais que a competência do aprendiz não abarque.

\section{A leitura em língua estrangeira}

De acordo com Kato (1999), durante muitos anos, o ensino de leitura em língua estrangeira resumiu-se ao estudo da gramática e do 
Revista Solta a Voz, v. 16, n. 175

vocabulário do texto. Dessa maneira chegava-se à sua tradução, entendida, assim, como o resultado da compreensão ou uma maneira de atingi-la. O estruturalismo, ao enfatizar a linguagem oral, propôs um modelo de leitura no qual a compreensão não depende da mediação da língua materna, mas da língua estrangeira oral em estudo. Assim, a habilidade de compreensão oral era um pré-requisito essencial para a compreensão da escrita, que associa a aprendizagem da leitura à decodificação sonora.

Para Bielsa (1990), o leitor em língua estrangeira pode experimentar uma considerável dificuldade ao enfrentar-se com um texto concreto pela primeira vez. Trata-se de dificuldade que não tem caráter somente lingüístico (pouco domínio das habilidades relacionadas com a decodificação), mas também pode estar relacionada com seu conhecimento sociocultural, ou ainda suas preferências por determinado tipo de texto.

De acordo com Nuttall (2000), o critério mais importante para a seleção do texto é o escolher textos motivadores e cativantes. Isso é possível desde que se desenvolvam, no aprendiz, habilidades de leitura e se tenha um texto que chame sua atenção, pois conteúdos interessantes fazem com que a tarefa dos aprendizes seja mais compensadora, e o trabalho em classe mais eficaz. Embora os clássicos literários sejam importantes, eles podem não ser exatamente um tipo de leitura cativante e motivadora, a principio. Desse modo, descobrir o que os estudantes lêem, seus textos preferidos em língua materna (LM), seria um bom procedimento a ser adotado em LE. Assim os materiais trabalhados exigem o seu monitoramento quanto à sua aceitabilidade, e os textos dos livros didáticos devem representar aqueles que os estudantes querem trabalhar, até chegar aos níveis de textos universitários.

\section{Problemas de interpretaÇão}

Ao analisar a vertente da compreensão, estamos estendendo a análise em direção ao que é chamado de significado comunicativo ou significado discursivo. Para Varó (1992), o significado discursivo diz respeito ao significado dos enunciados que se empregam na comunicação; na linguagem em ação. É difícil caracterizar esse significado como oracional ou literal, pois todo significado é sempre algo escorregadio e às vezes não-compreensível. Em alguns casos, o interlocutor transpor- 


\section{Revista Solta a Voz, v. 16, n. 1}

ta para seus enunciados aspectos significativos da mensagem de maneira implícita.

Para Cavalcanti (1989), os problemas de interpretação são resultantes de ambigüidades ou discrepâncias na negociação de significado através da interpretação retórica, problemas esses que podem não estar relacionados somente às escolhas semânticas do autor ou ao conteúdo proposicional, ou a ambos. Pode ser que o leitor não possua o conhecimento prévio exigido para poder abordar o texto; que o texto não ofereça nenhuma pista que permita ao leitor recorrer a esse conhecimento; que, finalmente, o conhecimento aplicado pelo leitor para interpretar $\mathrm{o}$ texto não coincida com o conhecimento que o autor pretendia.

\section{ConsideraÇões FinaIs}

Entender como os enunciados são interpretados durante o processo de leitura é compreender o resultado de uma comunicação entre autor e leitor. Durante esse processo, o leitor ativa seus processos de recepção da mensagem, utilizando estratégias de processamento do texto e de significados. Nessa perspectiva, o leitor assume vários papéis, que vão do analisador ao reconstrutor, passando polo construtor e cooperativo.

Como colocado neste artigo, o ato de ler é muito mais profundo do que a simples decodificação de palavras e entendimento do significado delas no texto. A cooperação é um fator relevante no processo de leitura e está presente tanto na produção como na recepção do texto. Relevante, também, é o grau de conhecimento de mundo compartilhado por autor e leitor, ou seja, o entorno social de cada um é ponto imprescindível para o ativamento dos significados contextuais.

A leitura em língua estrangeira envolve o entendimento de estruturas de base cultural, do contexto de produção do texto e das atitudes do leitor diante das dificuldades da leitura. Desse modo, muitos dos problemas apresentados pelos leitores são decorrentes da falta de concordância entre o entorno cognitivo na produção e na recepção do texto, e assim algumas estruturas podem não ser entendidas pelos leitores, porque estes simplesmente não compreenderam ou não conhecem o entorno cultural que envolve as palavras ou expressões apresentadas pelo texto. 
Revista Solta a Voz, v. 16, n. 1

\section{REFERÊNCIAS}

BIELSA, M. P. La teoría de los esquemas: actividades de prelectura. Barcelona: Universidad de Barcelona, 1990.

-Actividades de prelectura:activación y construcción del conocimiento previo. In: LOBATO, J.S. et al. La comprensión lectora en el aula de E/LE. Madrid: SGEL, 2000.

CANALE, M. De la competencia comunicativa a la pedagogía comunicativa del lenguaje In: LLOBERA, M. et al. Competencia comunicativa: documentos básicos en la enseñanza de lenguas extranjeras. Madrid: Edelsa, 1995.

CAVALCANTI, M.C. Interação leitor-texto: aspectos de interpretação pragmática. Campinas, SP: Ed. da Unicamp, 1989.

ESKEY, D. Holding in the bottom: an interactive approach to the language problems of second language readers. In: CARREL, J.D.; ESKEY, D. (Orgs.). Interactive aproachs to the second language reading. Cambridge: CUP, 1988.

ESPINET, M. D. La comunicación en la clase de español como lengua extranjera: orientaciones didácticas y actividades. Madrid: La Factoría de Ediciones/ Consejería de Educación y Ciencia de la Embajada de España en Brasil, 1997.

GRICE, P. Studies in the way of words. Cambridge: Harvard University Press, 1989.

HERNÁNDEZ, T.G. La comprensión lectora: la lectura como actividad didáctica. In: BELLO, P. et al. Didáctica de las segundas lenguas: estratégias y recursos básicos. Madrid: Editorial Santillana, 1990. p. 84-106.

KATO, M. A. O aprendizado da leitura. 5. ed. São Paulo: Martins Fontes, 1999.

KLEIMAN, A. Oficina de leitura: teoria e prática. 8. ed. São Paulo: Pontes, 2001.

LEVY, D. Comunicative goals and strategies. In: GIVÓN, T. (Org.). Syntax and semantics 12: discourse and syntax. Nova York: Academic Press, 1979. 
MAYOR, J. Estrategias de comprensión lectora. In: LOBATO, J.S. et al. La comprensión lectora en el aula de E/LE. Madrid: SGEL, 2000.

MEY, J. As vozes da sociedade: seminários de pragmática. Campinas, SP: Mercado de Letras, 2001.

NUTTALL, C. Teaching reading skills in a foreign language. Oxford: Macmillan Heinemann, 2000.

RUMELHART, D. E. Towards an interactive model of reading. In: DORNIC, S. (Org.). Attention and performance VI. New York: Academic Press, 1977.

VARÓ, E. A. La lingüística y la metodología didáctica de las lenguas extranjeras In: HOZ, V.G. Tratado de educación personalizada enseñanza y aprendizaje de las lenguas modernas. Madrid: Ediciones Rialp, 1992. p.19-107.

WIDDOWSON, H.G. O ensino de línguas para a comunicação. Trad.: José Carlos P. de Almeida Filho. São Paulo: Pontes, 1991.

Recebido em: 18 jan. 2005

Aceito em: 12 mar. 2005 